\title{
A heat transfer model describing burns to the skin from automotive airbags
}

\author{
G. N. Mercer* H. S. Sidhu*
}

(Received 4 January 2006; revised 12 August 2006)

\begin{abstract}
Automotive airbag usage is increasing with multiple airbags being fitted to many vehicles. Their ability to reduce morbidity associated with vehicle crashes is well documented; however, airbags have been identified as causing injuries in some instances. These injuries include abrasions, contusions, lacerations, and burns (thermal and chemical). Here we concentrate on the thermal burns due to contact with the hot expelled gases from the airbag or prolonged contact with the hot airbag itself. A heat transfer model is used to predict the likelihood and severity of these burns. It is shown that direct contact with high temperature gases venting from the airbag can indeed lead to burns and that burns from contacting the hot airbag material are possible but far less likely to occur in a correctly functioning airbag. These findings are supported by anecdotal evidence in the medical literature.
\end{abstract}

*School of Physical, Environmental and Mathematical Sciences, University of New South Wales at the Australian Defence Force Academy, Canberra, ACT 2600, Australia. mailto:g.mercer@adfa.edu.au

See http://anziamj.austms.org.au/V47EMAC2005/Mercer for this article, (C) Austral. Mathematical Soc. 2006. Published October 3, 2006. ISSN 1446-8735 


\section{Contents}

1 Introduction

C340

2 Heat transfer model

C342

3 The degree of skin burn

C343

4 Burns from venting gas

C344

5 Burns from direct airbag contact

C347

6 Conclusion

C351

References

C352

\section{Introduction}

New passenger vehicles are now commonly fitted with airbags with it being mandatory in some countries such as the USA. In the USA alone it was estimated that in 2003 there were 257 million airbags on the road (139 million drivers side and 118 million passenger airbags) [7]. This number will only increase as the number of vehicles fitted with airbags increases and the number of airbags per vehicle also increases with driver, passenger and side curtain airbags now common. It is estimated that by the year 2010 the penetration of airbags into the USA passenger car fleet will be essentially $100 \%$ [13].

The effectiveness of airbags in reducing fatalities and severe injuries is well documented but often overstated with seatbelt usage being far more effective $[2,4,17,24]$. Due to differences in seatbelt usage, airbags range in size from around 70 litres in USA models where seatbelt usage is lower to around 30 litres in Western European models [23]. The vehicle speed at which the airbag is triggered also varies due to seatbelt usage patterns 
with it set low in the USA market. In the USA it is estimated that there are 6.6 deployments per 1000 airbags per year which resulted in about 1.7 million deployments in 2003 [7].

There is a small but significant risk of injury from the airbag itself [23]. During inflation the airbag can reach speeds of up to $90 \mathrm{~m} / \mathrm{s}$ [13] and the most common form of injury is abrasion $(63.6 \%)$ from contact with the airbag. Burns from the airbag account for $7.8 \%$ of all injuries reported [1,9]. In a recent study of data from the years 1993 to 2000 in the USA, it was shown that $1.53 \%$ of front seat occupants exposed to an airbag deployment sustain an airbag induced burn [11].

Airbags work by a deceleration sensor triggering a highly exothermic chemical reaction that produces a large volume of hot gas, usually predominantly nitrogen, to inflate the airbag. This all happens in less than $100 \mathrm{~ms}$ from the time of impact. Gas temperature within the airbag can be up to $700^{\circ} \mathrm{C}[23]$ but are usually lower than this at deflation. The airbag deflates over a period of 1 to 2 seconds by vents located in the rear of the airbag in most instances.

There are two mechanisms for thermal burns from airbags. Firstly, burns from the hot gases being vented from the airbag during deflation. These are commonly on the hands and forearms of drivers due to the positioning of the exhaust vents on the rear of the airbag [22]. Secondly, burns are possible from direct contact with the material of a high temperature airbag [15, 21] although this is believed to be less common. Here we develop a mathematical model to analyse these two scenarios and determine the likelihood and severity of burns from each case. It is also possible to receive burns from melting of clothing, particularly lightweight synthetics, from the hot gas exhaust during deflation [3]. This scenario is not considered here. 


\section{Heat transfer model}

Heat transfer into the skin is assumed to be one-dimensional. This is reasonable since a typical thickness of skin under consideration for the duration of heating and types of burns is $2-3 \mathrm{~mm}$ and the region of heating due to the hot air or direct contact with the airbag has a length scale of $25 \mathrm{~mm}$ or larger. Hence the heat transfer is adequately described by the standard one dimensional heat diffusion model

$$
\rho C_{p} \frac{\partial T}{\partial t}=\frac{\partial}{\partial x}\left(k \frac{\partial T}{\partial x}\right),
$$

where $T$ is the temperature, $x$ the distance into the skin, $t$ time, $\rho$ the density of the skin, $C_{p}$ the specific heat, and $k$ the thermal conductivity.

The skin is modelled as three layers with differing thermal properties, the epidermis, the dermis and the subcutaneous layer having a total depth given by $L$. Values for these thicknesses will be used as is typically found on the forearms with the epidermis taken as $80 \times 10^{-3} \mathrm{~mm}$ thick, the dermis $2 \mathrm{~mm}$ thick and the subcutaneous layer $10 \mathrm{~mm}$ thick. Deeper layers are not required due to the relatively superficial nature of the burns studied. The thermal properties and dimensions used here are given in [12]. Previous skin burn models included a heat loss term to account for heat removal by blood perfusion in the dermis and subcutaneous layers [5, 12, 18, 19, 20]. This term was found to be unnecessary here as the time scales involved of around 1 second would mean that there is almost no heat removal by blood perfusion. It takes approximately 20 seconds for the body to react to an increase in temperature by increasing the blood flow [20] so this is not a relevant cooling mechanism in the scenario under investigation.

Initially the skin surface is cooler than the core body temperature. If the body is at equilibrium with its surroundings then the temperature increases linearly from the skin surface to the base of the subcutaneous region. Therefore the initial condition used here can be given by equation (2) where the 
temperature of the skin surface is $32^{\circ} \mathrm{C}$ and the temperature of the base of the the subcutaneous region is $37^{\circ} \mathrm{C}$ :

$$
T(x, 0)=32+(37-32) x / L .
$$

The inner boundary at the base of the subcutaneous layer is far enough from the skin surface that over the time span of interest the temperature there remains constant at $37^{\circ} \mathrm{C}$ so that

$$
T(L, t)=37 .
$$

The boundary condition on the skin surface depends on the scenario under investigation and is discussed later.

\section{The degree of skin burn}

Damage to the skin commences when the temperature in the tissue rises above $44^{\circ} \mathrm{C}$ [20]. By considering the damage to the tissue as a first order Arrhenius kinetics chemical reaction Henriques [10] devised a model for the thermal damage which has subsequently been used by numerous authors $[5,12,18,20]$. Define $\Omega(t)$ as the time dependent damage function then according to first order kinetics

$$
\frac{d \Omega}{d t}=P \exp \left(\frac{-\Delta E}{R(T+273)}\right) .
$$

Integrating for all time when the temperature is above $44^{\circ} \mathrm{C}$ gives the cumulative burn integral as

$$
\Omega(t)=\int_{0}^{t} P \exp \left(\frac{-\Delta E}{R(T+273)}\right) d \tau \text { for } \quad T>44,
$$

with the accepted values for the pre-exponential being $P=3.1 \times 10^{98} \mathrm{~s}^{-1}$ and the ratio of the activation energy to the universal gas constant as $\Delta E / R=$ 
$75,000 \mathrm{~K}[20] . \Omega$ is a highly nonlinear function and the generally used definitions of burns in terms of $\Omega$ are: first degree burn occurs at $\Omega=0.53$; second degree burn at $\Omega=1.0$; third degree burn at $\Omega=10^{4}$ [18]. The medical definition of burn degree is less quantitative with first degree burns only involving the epidermis, second degree burns involving the epidermis and part of the dermis, and third degree burns involving deeper tissue. We take the time to a first or second degree burn to be when the $\Omega=0.53$ and 1.0 contours respectively reach the base of the epidermis. A third degree burn is taken to be when the $\Omega=10^{4}$ contour reaches the base of the dermis.

The governing equation (1) is solved with the appropriate initial and boundary conditions using a time and space adaptive finite element package [8]. Due to its adaptive nature both space and time errors are minimized and more mesh points are used in regions of large gradients such as at the skin surface. All calculations are performed to a relative error tolerance of less than $0.1 \%$.

\section{Burns from venting gas}

Airbags deflate through vents usually at the rear of the airbag. It is these hot gases that are thought to be the cause of the majority of airbag induced burns with hands and forearms of drivers being particularly susceptible to burns due to the positioning of the vents [3]. The venting hot gases give a convective heat flux onto the skin of

$$
h\left(T_{g}-T(x, t)\right)=-k \frac{\partial T}{\partial x} \quad \text { at } \quad x=0,
$$

where $T_{g}$ is the temperature of the venting gas and $h$ is the heat transfer coefficient which depends on many factors such as the size of the vent, the velocity of the gas and the distance of the airbag from the skin surface. To be able to model the heat transfer to the skin it is necessary to determine appropriate values of $h$ to use. 
Consider a circular vent discharging a gas at velocity $u$ through a diameter $D$ and at a distance $H$ from the skin surface. Define the average Nusselt number $(\mathrm{Nu})$, Reynolds number $(\mathrm{Re})$ and Prandtl Number (Pr) as

$$
\mathrm{Nu}=h D / k_{g}, \quad \operatorname{Re}=u D / \nu, \quad \operatorname{Pr}=\nu / \alpha,
$$

respectively, where $k_{g}$ is the thermal conductivity, $\nu$ is the kinematic viscosity and $\alpha$ the thermal diffusivity of the gas. Martin [14] derived correlations for circular hot gas jets impinging on solid surfaces in terms of these average Nusselt, Reynolds and Prandtl numbers as

$$
\mathrm{Nu}=2 \operatorname{Pr}^{0.42} \operatorname{Re}^{0.5}\left(1+\frac{\operatorname{Re}^{0.55}}{200}\right)^{0.5} \gamma(H / D),
$$

which is valid for Reynolds numbers in the range $2000 \leq R e \leq 400,000$. Reynolds numbers of interest here are in the range $20,000 \leq R e \leq 200,000$ so the correlations are valid in this situation. The correction function $\gamma(H / D)$ is approximately unity for the range of $H / D$ under consideration here of $1 \leq H / D \leq 10$. Typical vent diameters range between $25 \mathrm{~mm}$ and $75 \mathrm{~mm}$. The typical gas velocity depends on the airbag volume, its deflation time and the size of the vent. Using typical values and rearranging equation (8) gives an estimate of the average heat transfer coefficient of between 100 and $2800 \mathrm{~W} \mathrm{~m}^{-2} \mathrm{~K}^{-1}$ with the most likely values being in the range 200 to $1200 \mathrm{~W} \mathrm{~m}^{-2} \mathrm{~K}^{-1}$. This is shown in Figure 1 which is a plot of the heat transfer coefficient as a function of the vent diameter for two typical airbag volumes of 30 and 70 litres and three different deflation times. The deflation time depends on factors such as the pressure exerted by the person impacting with the airbag and is typically 0.5 to 2 seconds.

Larger diameter vents give a lower heat transfer coefficient since the diverging jet impinges on a substantially larger area of skin surface. This results in a potential burn being less severe but over a larger area of skin. To reduce the potential burn capacity of the airbag venting gases the heat transfer coefficient should be as small as possible hence the diameter of the 


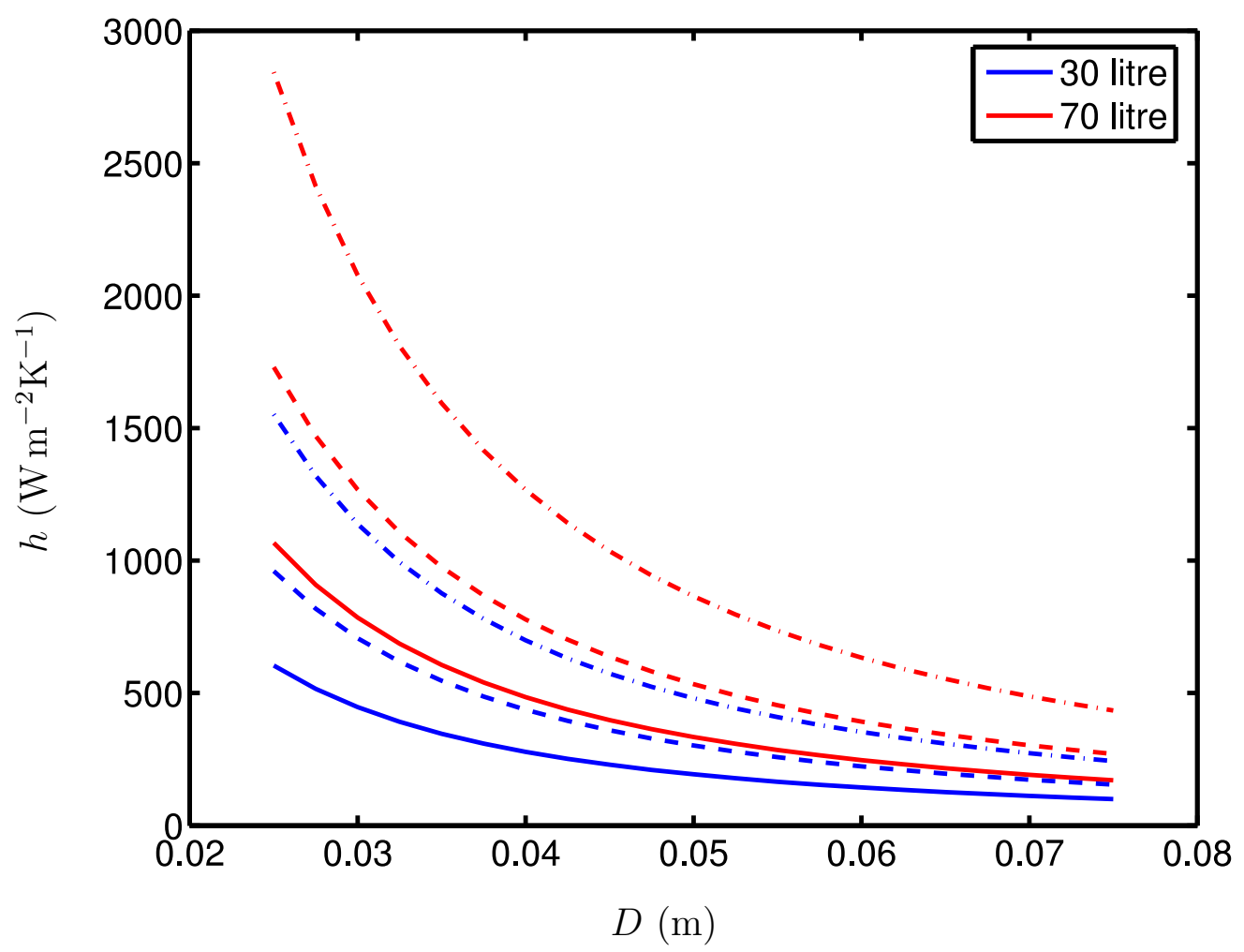

Figure 1: Average heat transfer coefficient versus vent diameter for two airbag volumes (30(blue) and 70(red) litre) and three deflation times 0.5 seconds (dot-dash), 1 second (dashed) and 2 seconds (solid). 
vents should be as large as possible and the deflation time as long as possible. Unfortunately these are conflicting requirements as larger vents usually lead to faster deflation times.

Equation (1) has been solved for heat transfer coefficients at the two extremes of the common values namely 200 and $1200 \mathrm{~W} \mathrm{~m}^{-2} \mathrm{~K}^{-1}$ with a gas temperature of $300^{\circ} \mathrm{C}$. Shown in Figure 2 are skin depth versus time plots of the three critical values of the damage function $\Omega$ corresponding to first, second, and third degree burns. First and second degree burns are taken to occur when the corresponding value of $\Omega$ passes through the epidermis/dermis boundary which in this particular case is at a depth of $80 \mu \mathrm{m}$. For the most extreme case considered ( $h=1200 \mathrm{~W} \mathrm{~m}^{-2} \mathrm{~K}^{-1}$ ) there is clearly the risk of substantial burn injury occurring within the time frame of the deflation of the airbag. A second degree burn is possible with only 0.1 seconds exposure to the hot venting gas. For the lowest value of the heat transfer coefficient of $h=200 \mathrm{~W} \mathrm{~m}^{-2} \mathrm{~K}^{-1}$ there is substantially less risk of a burn with exposures in excess of 0.5 seconds necessary for a first degree burn. This concurs with the observation that thermal burns do not always occur and are more likely with the larger volume airbags that have a higher heat transfer coefficient. These calculations give a good guideline to the timescales and burn severity encountered in practice.

\section{Burns from direct airbag contact}

Burns from contact with the hot airbag material had not previously been considered until cases were recently reported in the medical literature [15, 21]. Here we model this scenario to determine how likely these types of burns are. Hot gases within the airbag heat the material of the airbag during its inflated stage. It takes approximately one second for the airbag to reach thermal equilibrium where there is a linear drop in temperature across the airbag material. This is a similar timescale to the deflation of the airbag so 


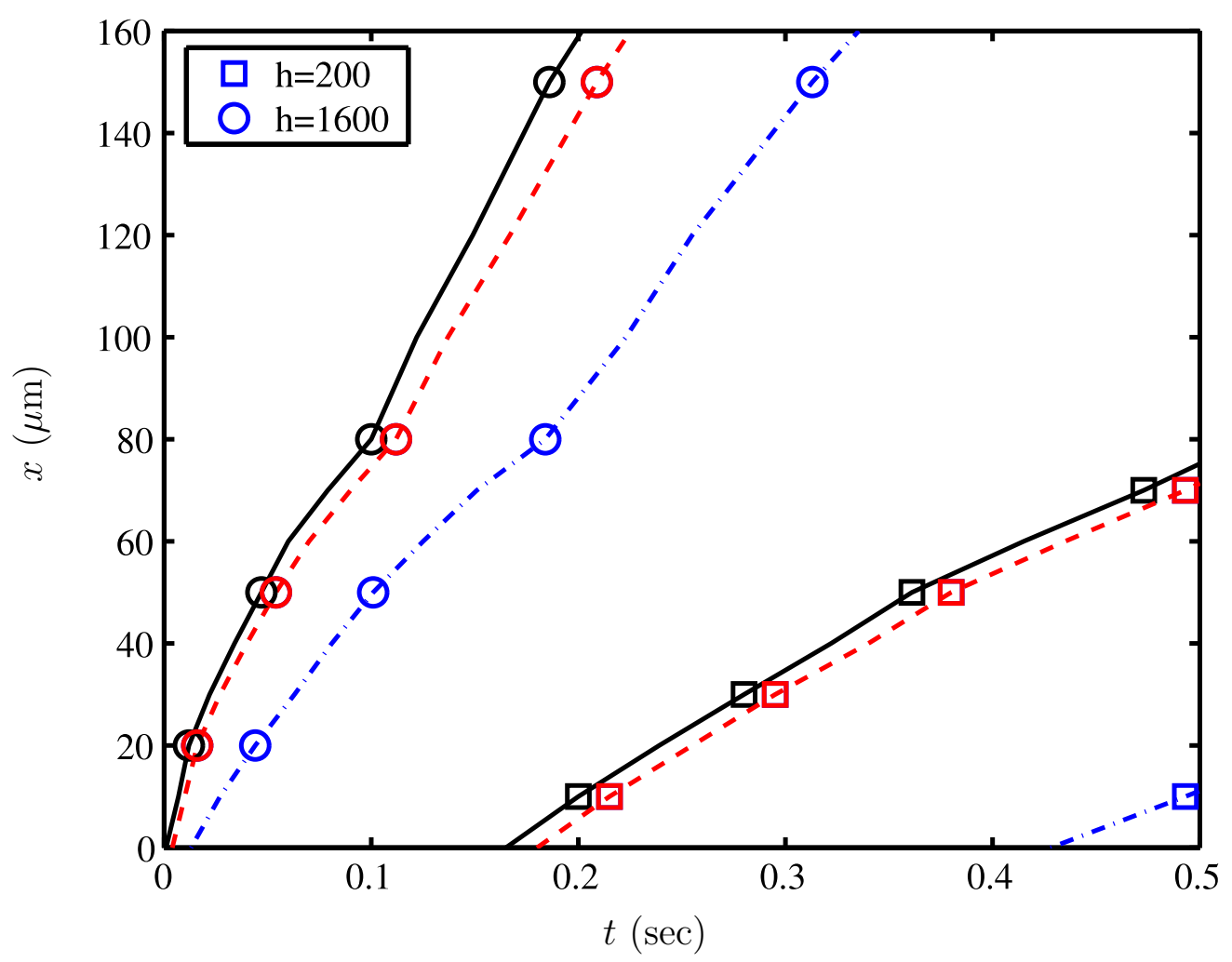

Figure 2: Depth of three types of burn damage versus time of exposure to the hot gas jet for the two likely extremes of the heat transfer coefficient $(h)$. Solid lines are first degree burn $(\Omega=0.53)$, dashed lines second degree burn $(\Omega=1.0)$ and dash-dot lines third degree burn $\left(\Omega=10^{4}\right)$. 
in most cases the occupant is not in contact with the hot airbag material for sufficient time to cause a burn as it has deflated before it heats up. If for any reason the deflation of the airbag is delayed, for instance partially blocked vents, then it could be possible to obtain a burn from direct contact with the airbag material.

Assume the airbag has thickness $A$ and that it has reached thermal equilibrium so that there is a linear temperature drop from the inside gas temperature, $T_{g}$, to the skin temperature. This is a worst case scenario as it is the case of largest heat transfer to the skin so any predictions obtained will be the lower limit of time taken to receive a burn from direct contact with the airbag material. The initial condition is then

$$
T(x, 0)=\left\{\begin{array}{l}
32+\left(32-T_{g}\right) x / A, \quad-A<x<0, \\
32+(37-32) x / L, \quad 0<x<L .
\end{array}\right.
$$

The inside of the airbag is taken to have a temperature given by the gas temperature so that the boundary condition is

$$
T(-A, t)=T_{g} .
$$

This again is a worst case scenario as in reality the gas temperature decreases with time as the airbag loses heat.

The majority of airbags are currently made from Nylon 6,6 yarn with thermal and physical properties of $C_{p}=1670 \mathrm{~J} \mathrm{~kg}^{-1} \mathrm{~K}^{-1}, \rho=1140 \mathrm{~kg} \mathrm{~m}^{-3}$, $k=0.25 \mathrm{~W} \mathrm{~m}^{-1} \mathrm{~K}^{-1}$ and a melting temperature of $260^{\circ} \mathrm{C}[6,16]$. Using these values with an airbag thickness of $0.5 \mathrm{~mm}$, numerical solutions to equation (1) are calculated with the above boundary and initial conditions. Shown in Figure 3 are skin depth versus time plots for first and second degree burns with three different internal airbag temperatures of 300,250 and $200^{\circ} \mathrm{C}$. The worst case scenario is that of a gas temperature of $300^{\circ} \mathrm{C}$ which is above the melting temperature of the airbag material. In fact the gas temperature can be expected to be below the melting temperature over a prolonged period as airbag melting is rarely seen. It takes considerably longer contact with 


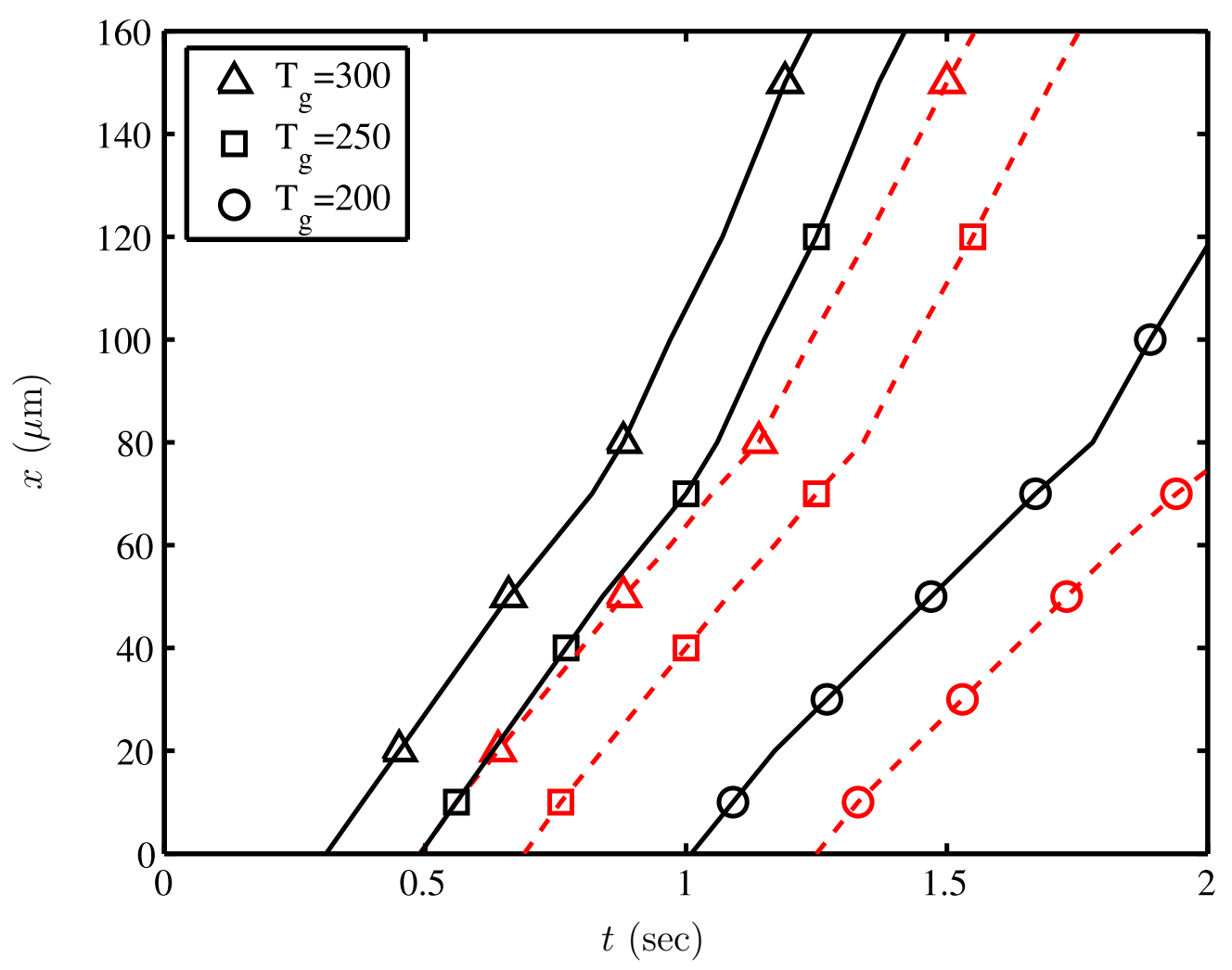

FiguRE 3: Depth of burn damage versus time of exposure to the hot airbag material for three values of the internal gas temperature $\left(T_{g}\right)$. Solid lines are first degree burn $(\Omega=0.53)$, dashed lines second degree burn $(\Omega=1.0)$. 
the hot airbag material to sustain even a mild burn when compared to the exposure to the hot expelled gas as shown in Figure 2. Even for the most pessimistic calculations with the airbag already at thermal equilibrium, the gas temperature above the melting temperature and extended inflated time of the airbag the contact time needed for a second degree burn is about 1 second. For more realistic parameter values the contact time needed increases to well over 2 seconds which is beyond normal operating conditions of airbags.

So although this shows that burns are possible from contact with the hot material it is far less likely than from exposure to the hot exhaust gases and is only likely in the event of a malfunction in the deflation of the airbag. A correctly functioning airbag is very unlikely to lead to burns from direct contact with the airbag material.

\section{Conclusion}

A heat transfer model has been developed to model burns from airbags in the two scenarios of hot airbag exhaust gases and contact with hot airbag material. Estimates have been made for the heat transfer coefficient from the hot gases to the skin and it is found that these hot gases easily cause burns. This has implications to the positioning and size of the vents used. The timescales involved for burns to occur from direct contact with the airbag material would in general preclude burns occurring from this mechanism provided the airbag is functioning correctly. If the airbag deflation is delayed or the occupant has a long contact exposure with the airbag then burns as seen recently by $[15,21]$ are indeed possible. 


\section{References}

[1] R. E. Antosia, R. A. Partridge, and A. S. Virk. Air bag safety. Annals of Emergency Medicine, 25:794-798, 1995.

http://dx.doi.org/10.1016/S0196-0644(95)70210-5. C341

[2] S. Barry, S. Ginpil, and T. O'Neill. The effectiveness of airbags. Accident Analysis and Prevention, 31:781-787, 1999. http://dx.doi.org/10.1016/S0001-4575(99)00041-X. C340

[3] A. M. Baruchin, I. Jakim, L. Rosenberg, and O. Nahlieli. On burn injuries related to airbag deployment. Burns, 25:49-52, 1999. http://dx.doi.org/10.1016/S0305-4179(98)00110-7. C341, C344

[4] P. Cummings, B. McKnight, F. P. Rivara, and D.C. Grossman. Association of driver air bags with driver fatality: a matched cohort study. BMJ, 324:1119-1122, 2002. C340

[5] K. R. Diller. Modeling thermal skin burns on a personal computer. Journal of Burn Care and Rehabilitation, 19:420-429, 1998. C342, $\mathrm{C} 343$

[6] Dupont automotive. http://www. automotive.dupont.com. C349

[7] Leonard Evans. Traffic safety. Science Serving Society, 2004. http://www.scienceservingsociety.com/traffic-safety.htm C340, C341

[8] FlexPDE ${ }^{\mathrm{TM}}$. http://www.pdesolutions.com. C344

[9] I. Hendrickx, L. L. Mancini, M. Guizzardi, and M. Monti. Burn injury secondary to air bag deployment. Journal of the American Academy of Dermatology, 46:S25-6, 2002.

http://dx.doi.org/10.1016/S0190-9622(02)70226-0. C341 
[10] F. C. Henriques. Studies of thermal injury V. The predictability and the significance of thermally induced rate processes leading to irreversible epidermal injury. Archives of Pathology, 43:489-502, 1947. C343

[11] M. V. Jernigan, A. L. Rath, and S. M. Duma. Analysis of burn injuries in frontal automobile crashes. Journal of Burn Care and Rehabilitation, 25:357-362, 2004. C341

[12] S. C. Jiang, N. Ma, H. J. Li, and X. X. Zhang. Effects of thermal properties and geometrical dimensions on skin burn injuries. Burns, 28:713-717, 2002.

http://dx.doi.org/10.1016/S0305-4179(02)00104-3. C342, C343

[13] R. Kent, D. C. Viano, and J. Crandall. The field performance of frontal airbags: A review of the literature. Traffic Injury Prevention, 6:1-23, 2005. http://dx.doi.org/10.1080/15389580590903131. C340, C341

[14] H. Martin. Heat and mass transfer between impinging jets and solid surfaces. Advances in Heat Transfer, 13:1-60, 1977. C345

[15] F. Masaki. A new category of contact burn resulting from air bag infusion. Burns, 31:118-119, 2005. http://dx.doi.org/10.1016/j.burns.2004.07.013 C341, C347, C351

[16] Matweb: Material property data. http://www.matweb.com. C349

[17] G. McGwin, J. Metzger, J. Alonso, and L. Rue. The association between occupant restraint systems and risk of injury in frontal motor vehicle collisions. The Journal of Trauma, 54:1182-1187, 2003. URL C340

[18] E. Y. K. Ng and L. T. Chua. Comparison of one- and two-dimensional programmes for predicting the state of skin burns. Burns, 28:27-34, 
2002. http://dx.doi.org/10.1016/S0305-4179(01)00066-3. C342, C343, C344

[19] H. H. Pennes. Analysis of tissue and arterial blood temperatures in resting human forearm. Journal of Applied Physiology, 1:93-122, 1948. http://jap.physiology.org/cgi/reprint/1/2/93 C342

[20] D. A. Torvi and J. D. Dale. A finite element model of skin subjected to a flash fire. Journal of Biomechanical Engineering, 116:250-255, 1994. C342, C343, C344

[21] Y. Tsuneyuki, N. Gozo, F. Masaki, and M. Osamu. Facial contact burn caused by air bag deployment. Burns, 29:189-190, 2003. http://dx.doi.org/10.1016/S0305-4179(02)00286-3. C341, C347, C351

[22] D. Ulrich, N. Ernst-Magnus, P. Fuchs, and N. Pallua. Burn injuries caused by air bag deployment. Burns, 27:196-199, 2001. http://dx.doi.org/10.1016/S0305-4179(00)00091-7. C341

[23] L. A. Wallis and I. Greaves. Injuries associated with airbag deployment. Emergency Medicine Journal, 19:490-493, 2002. http://dx.doi.org/10.1136/emj.19.6.490 C340, C341

[24] P. L. Zador and M. A. Ciccone. Automobile driver fatalities in frontal impacts: air bags compared with manual belts. American Journal of Public Health, 83:661-666, 1993.

http://www.ajph.org/cgi/content/abstract/83/5/661 C340 